\title{
Structure-preserving representations, constitution, and the relative a priori
}

\author{
Thomas Mormann' ${ }^{1}$ (D)
}

Received: 8 September 2017 / Accepted: 9 March 2018

(C) Springer Science+Business Media B.V., part of Springer Nature 2018

\begin{abstract}
The aim of this paper is to show that a comprehensive account of the role of representations in science should reconsider some neglected theses of the classical philosophy of science proposed in the first decades of the twentieth century. More precisely, it is argued that the representational accounts of Helmholtz and Hertz, in which the concept of structure-preservation plays an essential role, still deserve attention for contemporary debates. Following Reichenbach, structure-preserving representations provide a useful device for formulating an up-to-date version of a (relativized) Kantian a priori. An essential feature of modern scientific representations is their mathematical character. That is, representations can be conceived as (partially) structure-preserving maps or functions. This observation suggests an interesting but neglected perspective on the history and philosophy of this concept, namely, that structure-preserving representations are closely related to a priori elements of scientific knowledge. Reichenbach's early theory of a relativized constitutive but nonapodictic a priori component of scientific knowledge provides a further elaboration of Kantian aspects of scientific representation. To cope with the dynamic aspects of the evolution of scientific knowledge, Cassirer proposed a re-interpretation of the concept
\end{abstract}

\footnotetext{
A first version of this paper was presented at the International Conference on Modelling and Representation. How to Make World(s) with Symbols that took place at the University of the Basque Country (UPV/EHU) in Donostia-San Sebastian (Spain) on December 10-12, 2015. My thanks to two anonymous referees for this journal for insightful comments and criticism. The author's work was supported by the research project "Representation and Anticipation: RRI modelling in emerging sciences and technologies" (FFI2015-69792-R), funded by the Spanish Ministry of Economy and Competitiveness, Government of Spain.
}

$凶$ Thomas Mormann thomasarnold.mormann@ehu.eus

1 Department of Logic and Philosophy of Science, University of the Basque Country UPV/EHU, Avenida de Tolosa 70, 20080 Donostia-San Sebastian, Spain 
of representation that conceived of a particular representation as only one phase in a continuous process determined by pragmatic considerations. Pragmatic aspects of representations are further elaborated in the classical account of C.I. Lewis and the more modern of Hasok Chang who characterized in certain relativized representational a priori assumptions as pragmatically justified metaphysical arguments.

Keywords Representation · Relative a priori · Structure preservation · Ernst Cassirer · Hasok Chang · Hans Reichenbach · Clarence Irving Lewis

\section{On the vicissitudes of the concept of representation in twentieth century philosophy of science}

The concept of representation has not yet found a secure place on the agenda of philosophy of science. Some philosophers have flatly denied that it could be of any use in epistemology or philosophy of science. They have claimed that the concept of representation leads us into a hopeless maze of pseudo-questions without answers. According to them, epistemology based on the notions of negotiation and interpretation should replace epistemological accounts based on "representation".

One such philosopher was Richard Rorty. According to him, there were two different camps in philosophy: one was the reactionary group of representationalists who belonged to the past; and the other consisted of "progressive", i.e., anti-representationalist philosophers who Rorty considered the philosophers for the twenty-first century:

Representationalists [are those philosophers] who find it fruitful to think of mind or language as containing representations of reality. [Anti-representationalist philosophers] attempt to eschew discussions of realism by denying that the notion of ,representation“... has any useful role in philosophy. Representationalists typically think that controversies between idealists and realists were fruitful and interesting (my emphasis). Antirepresentationalists typically think both sets of controversies pointless (Rorty 1991, p. 2).

According to Rorty, the typical adherents of representationalism in the twentieth century were Frege, Russell, Husserl, Tarski, and Carnap. In contrast, Quine, Sellars, and Strawson were said to be the pioneers of the new anti-representationalist dogma.

Obviously, there is something wrong with Rorty's simple binary classification. Take, for instance, the case of Carnap. During his whole philosophical career this allegedly arch-representationalist maintained that the traditional debate between idealism and realism was pointless. Already in the Aufbau, one finds the thesis:

... the so-called epistemological schools of realism, idealism, and phenomenalism agree within the field of epistemology. Construction theory (= the Aufbau's theory of constitution) represents the neutral foundation which they have in common. They diverge only in the field of metaphysics, that is to say (if they are meant to be epistemological schools of thought), only because of a transgression of their proper boundaries. Aufbau (1928, § 178). 
The concept of representation has a rich history that has been completely ignored by many self-proclaimed anti-representationalists. For instance, Rorty's contention that representationalism subscribes to a copy theory of knowledge according to which the aim of scientific knowledge was to produce an accurate copy of the world is quite wrong. Kant had vigorously argued against any kind of "kopeyliche Betrachtung" ("copy-like consideration") (cf. Kant 1787, A318/B375). ${ }^{1}$ Irrespective of all their internal differences and their various deviations from Kant, all neo-Kantians took this doctrine to heart, and they all emphasized that representation did not have the intention to produce an accurate copy of the world-in contradiction to Rorty's claim that all "representationalists" subscribed to this thesis. Rorty was not interested, however, in details concerning matters of representation. Instead, he was content with sweeping generalities, as is already shown by his assessment of Carnap's philosophy.

According to Rorty, we should fall back onto a more or less trivial concept of representation:

We should restrict the term "representation" to things like maps and codes things for which we can spell out rules of projection which pair objects with other objects, and thus embody criteria of accurate representation. If we extend the notion of representation beyond such things, we shall burden ourselves with a lot of philosophical worries we need not have. In particular, if we worry about what rules of projection connect sentences like "F = MA" with bits of reality, we get nowhere (Rorty 1993, p. 126).

Rorty gave no reason for why "we get nowhere" when we worry about what rules of projection connect sentences like $\mathrm{F}=\mathrm{MA}$ with what bit of reality. Moreover, he gave no hint what to do philosophically with sentences such as F=MA, which apparently correspond somehow with bits of reality and form an essential component of our scientific knowledge, the interpretation of which remains an essential task of philosophy of science.

Today, after more than 30 years since Rorty put forward his onslaught on the concept of representation, his attack seems rather dated. The concept of representation is still very much alive and on the agenda of philosophy of science, as is evidenced by the wealth of recent books and papers on this topic. ${ }^{2}$

The tides have changed, and for some time we have been experiencing a new vogue in representationalist philosophy. Today, a philosopher of science would hardly offer an

\footnotetext{
1 According to Kant, knowledge does not intend to yield a copy of what is known but rather to understand its "architecture". This thesis was a leit-motif of Ernst Cassirer's Neo-Kantian "critical theory" of science. In his work, Cassirer emphasized the importance of this insight of Kant by repeatedly conceiving of "architecture" as "functional architecture".

2 Without claiming completeness or judging their importance, let me just mention the following booklength treatises: Giovanni Boniolo, On Scientific Representations. From Kant to a New Philosophy of Science (2007), Ronald Giere, Scientific Perspectivism (2006), Steven French, The Structure of the World, Metaphysics and Representation (2014), Bas van Fraassen, Scientific Representation (2006).

An early voice against Rorty's "anti-representationalist" crusade was Ian Hacking's Representing and Intervening (Hacking 1983). According to Hacking "The first peculiarly human invention is representation. Once there is a practice of representing, a second-order concept follows in train. This is the concept of reality, a concept which has content only when there are first-order representations." (Hacking 1983, p. 136). For a discussion of Hacking's thesis, see Rheinberger (2010, chapter 6).
} 
openly anti-representational account that claims the concept of representation should play no role in philosophy of science.

This fact does not imply that we already know well the role of representation in science and how this concept works. As Giere pointed out, the opinion is still widely held "that scientists represent the world primarily in linguistic terms and so that scientific representation is to be understood as a two-place relationship between linguistic entities and the world" (cf. Giere 2006, p. 62). This opinion may not be completely wrong but is at most only the beginning of a satisfying answer.

Giere's suggestion to shift the focus of the discussion on the practice of scientific representing is certainly a step in the right direction but nevertheless leaves out an essential feature of modern scientific representation, namely, its mathematical character, which is encapsulated in the fact that representations in science can be mathematically conceived as (partially) structure-preserving maps or functions. Acknowledging the essential role of mathematics for scientific representations does not go against the practical character of mathematics. On the contrary, emphasizing the role of mathematics in matters of scientific representations opens an interesting neglected perspective on the history and philosophy of this concept, namely, that representations as (partially) structure-preserving maps are closely related to the a priori elements of scientific knowledge. This thesis may be elucidated by briefly recalling an essential ingredient of Kant's original account that still plays an essential role in the contemporary discussion of the a priori, namely, the role the a priori plays in the constitution of the objects of science. For the purposes of this paper, it suffices to address Euclidean geometry as a typical example of a constitutive a priori. For Kant, Euclidean geometry of space functioned as a constitutive framework for physics that was not empirical; rather, it first rendered possible properly empirical discoveries (cf. Friedman 2001, p. 62). Euclidean geometry can be characterized as a representational a priori in that it enables us to represent (and thereby to constitute) physical phenomena such as the paths of particles, their velocities, and the forces that act on them geometrically, i.e., by certain structures of a mathematical space-for instance, by vectors, tensors, and other geometrical constructs. ${ }^{3}$ How this is done is described in terms of (partial) structure preservation and related mathematical concepts. ${ }^{4}$

After the advent of Einstein's relativity theories, one knows, however, that the constitutive representational framework of Euclidean geometry is not (as Kant thought) the only possible one. There is more than one constitutive geometrical framework, and these different frameworks compete with each other with respect to simplicity, fruitfulness, precision, and possibly other theoretical and practical virtues. The plurality of different constitutive frameworks leads to a competition between them. For the philosophical discussion concerning the role of a priori aspects of scientific knowledge, this means that pragmatic aspects of the a priori become increasingly important in postKantian philosophy of science (see Sects. 4, 5). More precisely, I address this issue

\footnotetext{
3 There is no reason to expect that every constitutive a priori (Kantian or post-Kantian) is representational in the sense just described. For instance, Einstein's "light principle", which is a constitutive principle of relativity theory, is not a representational a priori principle.

${ }^{4}$ For more detail on how such a geometrical representation works, see Reichenbach (1920) and Sect. 3 of this paper.
} 
of the pragmatic relation among constitution, representation, and (partial) structure preservation as follows.

The next section recalls that the origins of the project of conceiving of representation as an essentially practical relation with more than two components. This project can be traced back (in embryonic form) to the very beginnings of a modern post-Kantian representational account of scientific cognition and scientific knowledge in particular, namely, the one that Helmholtz's presented in The Facts of Perception (Von Helmholtz 1878). Helmholtz's approach was essentially Kantian, ${ }^{5}$ in that it was based on the Kantian distinction between the two worlds of noumena and phenomena. ${ }^{6}$ As will be explained in more detail in the next section, the world of noumena is represented by the world of phenomena structured by a similarity structure. This similarity structure can be understood as a kind of very simple spatial structure. Second, Helmholtz's approach was based on a mathematical account of representation that described representations as (partially) structure-preserving maps between two realms (in Helmholtz's case the worlds of noumena and phenomena). These two aspects of Helmholtz's approach nicely match, since the notion of (partial) structure preservation can be conceived as a form a (relativized and historized) form of a Kantian a priori. Helmholtz was just an early member the group of scientists and philosophers who attempted to update Kant's philosophy of science in such a way that it took into account the achievements of post-Kantian science.

The aim of this paper is to bring together these two strands of thought in order to contribute to a better understanding of the role of representations in scientific knowledge. Painted with a broad brush, scientific theories are representations, i.e., conceptual tools made for achieving cognitive and other pragmatic aims. From such a pragmatic point of view, representations do not simply represent the world as it is but contain rules for interacting with it, meaning that there is no (or should be no) exclusive disjunction between "representing" and "intervening". Rather, representations in science are to be thought of as "intervening representations".

Scientific theories do not offer true descriptions of the world, nor the most truth-like ones, they are pictures of nature that allow one to give a uniform and comprehensive account of the totality of phenomena. Theories are attempts, made by the cognizing subject, to grasp the empirical data and give them cognitive significance. The role of representations is not limited to recording in a coherent and economic way what is already empirically known. Representations also have to predict future events.

\footnotetext{
5 This holds even though Helmholtz did not agree with all Kantian theses, for instance, according to standard scholarship, he denied the a priori character of Euclidean geometry. Recently, Friedman and Ryckman aimed to show that Helmholtz's theory of space actually was in line with a Kantian philosophy of science in which the original apodictic Kantian a priori is replaced by relativized more flexible a priori. The general Kantianism of Helmholtz to be discussed in this paper does not depend on this (cf. Friedman 1997; Ryckman 2005).

6 Whether Helmholtz's "2-world"-interpretation of Kant's account (the world of noumena and the world of phenomena, respectively) faithfully preserves Kant's original intentions may well be doubted. Most experts claim that Kant's account was more subtle than Helmholtz realized. Further, one may criticize Helmholtz's understanding of Kantian "Dinge-an-sich" and "Erscheinungen". For a detailed, recent discussion of these issues, see Oberdan (2015). These problems need not concern us here.
} 
Representations do not tell us how things are in themselves but, in Kantian jargon, how "our conceptions of things" are. They have a double face: they are both what one knows and that by means of which one knows. They are hypothetical constructions made to grasp reality. Thus, reality plays an indispensable role in evaluating them. Only by appealing to experience they can be confirmed or disconfirmed.

If the Kantian character of (partial) structure preservation is recognized as an essential feature of scientific representation in general, then it becomes plausible that other features of scientific representation may be fruitfully conceived of in a broadly Kantian perspective. The general claim of this paper is to show that this is indeed the case.

In Sect. 3, which deals with some aspects of the early Reichenbach's philosophy of science, I would like to show that the issue of structure preservation in scientific representations is closely related to a classical topic in twentieth century philosophy of science, namely, what to do with the Kantian legacy of the a priori component of scientific knowledge. On the one hand, the traditional apodictic and constitutive Kantian a priori had turned obsolete; on the other hand, some kind of a flexible historized a priori was arguably indispensable for a rich and comprehensive description of scientific knowledge. ${ }^{7}$

Any representational account, by distinguishing between the realms of the represented and the representing, seems to be threatened by the fundamental skeptical objection that there is no guarantee that the account establishes a valid connection between the two realms. The neo-Kantian philosopher Ernst Cassirer in Substance and Function (1910) addressed this issue and noted that representation in science should be conceived as homogeneous representation (in a sense to be specified) for which this general skepticism turned out to be pointless. Cassirer's argument is treated in Sect. 4 and naturally leads to a pragmatic account of representation. This connection is more explicitly elaborated in Sect. 5 by relying on the classical account of C.I. Lewis and the more modern of Hasok Chang.

\section{Towards a pluridimensional account of representation: from Helmholtz to Giere}

As a point of departure for elucidating the role of representation in modern science, let us recall Helmholtz's famous account of perceptual knowledge that clearly exhibits both the Kantian and mathematical aspects:

Our sensations are indeed effects produced in our organs by external causes, and how such an effect expresses itself naturally depends quite essentially upon the kind of apparatus upon which the effect is produced. Inasmuch as the quality of our sensation gives us a report of what is peculiar to the external influence by which it is excited, it may count as a symbol of it, but not as an image. For from an image one requires some kind of alikeness with the object fo which it is an image ... But a sign need not have any kind of similarity at all with what it is the

\footnotetext{
7 This paper deals with only Reichenbach's earliest account of coordination as a priori, which he presented in Reichenbach (1920). As is well known, later, under the influence of Schlick and Carnap, Reichenbach considerably changed his view (cf. Reichenbach 1924, 1928; Friedman 1999a, b).
} 
sign of. The relation between the two of them is restricted to the fact that like objects exerting an influence under like circumstances evoke like signs, and that therefore unlike signs always correspond to unlike influences (Von Helmholtz 1878, p. 122).

Originally, Helmholtz conceived of his account as an account of perception only. But, it is easily generalized from perception to a model of cognition and knowledge in general. That is to say, replacing "perception" with "cognition", we arrive at a symbolic, more precisely, structuralist account of cognition and knowledge. According to this account, we never know the essence of objects (whatever this may be) but at most the structural relations existing between them. ${ }^{8}$

Helmholtz's 2-level representational account may be considered a radical (arguably oversimplified) Kantianism: It conceives perception, and more generally cognition, as a map $\mathrm{W} \longrightarrow \mathrm{S} \longrightarrow \mathrm{S}$ between the world $\mathrm{W}$ of objects (the "real world") and the world $\mathrm{S}$ of sensations or symbols. On $\mathrm{W}$ and $\mathrm{S}$ are defined binary likeness relations $\sim \mathrm{W}$ and $\sim_{\mathrm{S}}$, respectively. If $\mathrm{a} \sim_{\mathrm{W}} \mathrm{b}$ and $\mathrm{x} \sim \mathrm{S}$ y obtain, this is to be interpreted as the state of affairs that "the objects a and b are similar to each other" and "the sensations $\mathrm{x}$ and $\mathrm{y}$ are similar to each other". The only law that a good representation, i.e., an accurate "world picture", has to satisfy requires that it provides us with a map $\mathrm{W} \longrightarrow \mathrm{S} \longrightarrow \mathrm{S}$ that is structure-preserving in the following elementary sense:

$$
\forall \mathrm{a} \forall \mathrm{b}\left(\mathrm{IF} \mathrm{a} \sim_{\mathrm{W}} \mathrm{b} \text { THEN s }(\mathrm{a}) \sim_{\mathrm{S}} \mathrm{s}(\mathrm{b})\right)
$$

A robustly realistic interpretation of $(*)$ would assume that the relation $\sim_{S}$ between our sensations "reflects" a structurally similar relation $\sim_{\mathrm{W}}$ between objects of the noumenal world. This interpretation is not, however, the only possibility: A more cautious reading would be that the relation $\sim_{S}$ induces a relation $\sim \mathrm{W}$ on the elements of the world $\mathrm{W}$ by the stipulation $\mathrm{a} \sim \mathrm{W} \mathrm{b}:=\mathrm{s}(\mathrm{a}) \sim \mathrm{S} \mathrm{s}(\mathrm{b}) .{ }^{9}$ This reading is not simply to be characterized as "weaker"; it also emphasizes the constitutive, "order-generating" role of representation. ${ }^{10}$

\footnotetext{
8 Oberdan recently pointed out that the path from Helmholtz's structural theory of perception to the structural account of knowledge of early logical empiricism (particularly Schlick) was far from straight and direct. For the details see Oberdan (2015).

9 Reichenbach seems to have favored an interpretation of this kind when noting that by empirical measurement " $[\mathrm{t}]$ he only fact that can be determined is whether two numerical values derived from two different measurements are the same. We cannot know whether a coordination with this result always refers to the same element in the real world" (Reichenbach 1920, p. 45).

10 It is worth mentioning that the aspect of order generation (or, more generally, structure generation) plays an important role for the theory of mathematical representation. It is not restricted to the very simple example of Helmholtz's similarity. Mathematically, the following examples are a bit more advanced: Let $\mathrm{X} \longrightarrow \mathrm{f} \longrightarrow \mathrm{Y}$ be a set-theoretical map between sets $\mathrm{X}$ and $\mathrm{Y}$, where $\mathrm{Y}$ is endowed with an order relation $\leq \mathrm{Y}$. Then $\leq \mathrm{Y}$ induces an order relation $\leq \mathrm{X}$ on $\mathrm{X}$ by the stipulation $\mathrm{X} \leq \mathrm{X} \mathrm{X}^{*}$ iff $\mathrm{f}(\mathrm{x}) \leq \mathrm{Y} f\left(\mathrm{X}^{*}\right)$. Analogous constructions may be carried out for many other mathematical structures, e.g., topological ones. Whether such a structure-induction makes sense empirically has to be determined empirically. Reichenbach was well aware of this fact, for instance, when he asserted that the difference between rational and irrational numbers does not make sense for empirical realms. In philosophy of physics the general problem of which elements of a formalism correspond to something in the real world and which do not has been called the problem of "surplus formal structure" (cf. Redhead 1975, p. 88).
} 
The model underlying Helmholtz's structural realist account of perception and, more generally, of cognition is, of course, very abstract. Later authors have further elaborated its basic elements, such as symbolism, structural realism, and epistemologico-activism (pragmatism). As an early example of such an elaboration, one may consider Hertz's well-known thesis that brings the conceptual and experimental activity of the symbolizing subject more clearly into play than did Helmholtz ${ }^{11}$ :

We form for ourselves images or symbols of external objects; and form that which we give them is such that the necessary consequents of the images in thought are always the images of the necessary consequents in nature of the things pictured must be the images of the consequents. In order that this requirement may be satisfied, there must be a certain conformity between nature and our thought. Experience teaches us that the requirement can be satisfied, and hence that such a conformity does in fact exist (Hertz 1894, p. 1).

Hertz's informal description of the representational activity of science may be translated into a diagrammatical language as follows: Let the set of "external objects" be denoted by E and the set of "images or symbols" be denoted by S. Then, the following commutative diagram may be used to capture the essential structure of Hertz's account:

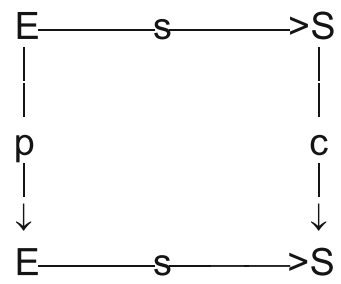

$$
\cos (e) \quad=\quad \operatorname{sep}(e)
$$

which is to be read as follows: Relating an external object e to its symbolic image s(e) and submitting s(e) to an symbolic calculation c leading to the symbol c•s (e) amounts to the same as submitting the external object e to the empirical process $\mathrm{p}$ with the result of $\mathrm{p}(\mathrm{e})$ and then submitting $\mathrm{p}(\mathrm{e})$ to the symbolic calculation $\mathrm{c}$ leading to the final result of $c^{\bullet}$ s $(e)$.

It should be noted that Hertz goes well beyond Helmholtz's approach ${ }^{12}$ by emphasizing the possibility of several different images or symbols $S, S^{\prime}, \ldots$ of one and the same domain E. Diagrammatically, this possibility amounts to the existence of other diagrams of the same type:

\footnotetext{
11 It has been noted that Helmholtz's concept of "pictures" and Hertz's concept of "symbols" are different (cf. Heidelberger 1998, p. 21ff). This does not affect the present discussion, however. The important point is that both can be couched in the framework of structure-preserving representations and commutative diagrams.

The physicist has to assess which picture is the best according to the criteria of permissibility, correctness and adequacy (cf. Hertz 1894; Lützen 2005; Majer 1998).

12 In (**), Helmholtz's approach is represented by the diagram $\mathrm{E} \longrightarrow \mathrm{S} \longrightarrow \mathrm{S}$, which may be conceived as a part of the entire commutative diagram.
} 


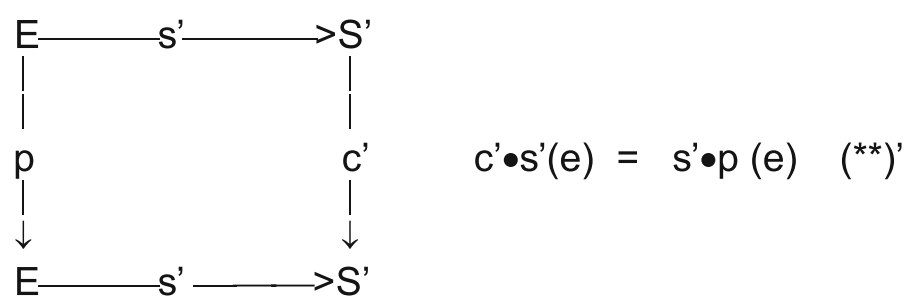

The existence of several pictures leads, as Hertz observed, to an inextricable underdetermination of scientific theorizing that can be reduced only by pragmatic considerations: "One picture may be more suitable for one purpose, another for another. Only by gradually testing many pictures can we finally succeed in obtaining the most appropriate" (Hertz 1894, p. 3). By emphasizing the active role of the "picturing" or "symbolizing" subject, Hertz's account goes well beyond that of Helmholtz's. This account has been aptly described by Majer as follows:

According to Hertz, usually we encounter the world actively, creatively and con-structively, in accordance with our manual and mental abilities; we are not simply passive receivers and describers .... (Majer 1998, p. 235).

A common idealizing factor of Helmholtz's and Hertz's representational accounts is approximation, which these authors accept without problematizing it. Let us consider in detail the case of Hertz. The essential feature of this account is that the various mappings in the diagrams of type (**) do commute in the sense that the two paths of (**) from the upper left to the lower right vertex yield the very same results. In reality, this claim is a highly counterfactual idealization, i.e., theoretical predictions and experimental results almost never exactly coincide (and if they do, this coincidence is to be considered merely a fortunate coincidence). This conclusion is, of course, nothing new for scientists and philosophers of science, as is witnessed by Pierre Duhem and many others. At various occasions in his opus magnum The aim and structure of Physical Theory, Duhem asserted that the correspondence between "practical facts" and "symbolic facts" established by an empirical theory is of such a kind that

A symbolic formula ... can be translated into concrete facts in an infinity of different ways, because all these disparate facts admit the same theoretical interpretation (Duhem 1954, p. 150)

Similarly, he asserted that

The same practical fact may correspond to an infinity of logically incompatible theoretical facts; the same group of concrete facts may be made to correspond in general not with a single symbolic judgment but with an infinity of judgments different from one another and logically in contradiction with one another (ibid., 152).

In a diagrammatic language, Duhem's theses amount to the claim that in the diagrams $(* *)$ and $(* *)^{\prime}$, the maps s and $\mathrm{s}^{\prime}$ are not 1-1 but many-valued. Moreover, only under strong idealizing assumptions can these diagrams be considered commutative.

It has occasionally been objected against Helmholtz's approach that it ignores the essential role of the perceiving subject. This objection is a bit unfair. After all, the 
representing map between the world $\mathrm{W}$ of transcendent objects and the world $\mathrm{S}$ of sensations is not simply there, it is created by us, depending at least partially on the nature of our perceptual and conceptual apparatus (cf. Helmholtz 1977 (1878), p. 121). Moreover, Helmholtz repeatedly emphasized the importance of the specific circumstances that accompany the production of signs and how relevant it is to vary the circumstances in order to find the relevant aspects of the appearances that remain invariant:

For if comprehending ("begreifen") means forming concepts ("Begriffe"), and in the concept we gather together and bind together whatever like characteristics they bear, it then results quite analogously that the concept of a series of appearances alternating in time must seek to bind together that which remains alike in all stages (Helmholtz 1977 (1878), pp. 138-139). ${ }^{13}$

In summary, Helmholtz did not completely ignore the empirical and pragmatic aspects of the production of cognitively and perceptually relevant signs or symbols. It may be that they did not play the role they deserve in Helmholtz's and Hertz's accounts; however, they certainly are not completely absent, and it seems not too difficult to make them more explicit. Thereby, one may hope to arrive at a concept of scientific representation that does full justice to the role of scientific practice in matters representational.

One influential proposal of how such a concept can be achieved is Ronald Giere's tetradic account of scientific representation (cf. Giere 2004). Giere proposed to conceive scientific representations as tetradic relations of the following kind:

\section{$\mathrm{S}$ uses $\mathrm{X}$ to represent $\mathrm{W}$ for purposes $\mathrm{P} . \quad(* * *)$}

Mildly formalized, this account amounts to conceiving of scientific representations as tetradic relations $\mathrm{R}(\mathrm{S}, \mathrm{X}, \mathrm{W}, \mathrm{P})$ whose variables can take the following values: $\mathrm{S}$ can be anything from an individual scientist to a scientific community, understood synchronically or diachronically; $\mathrm{X}$ is a model (or a class of models) in a broad sense, i.e., $\mathrm{X}$ may be a linguistic or a mathematical device that serves a representational purpose of some kind; W stands for a piece of the real world, a (kind of) thing, event, or system; and finally, $\mathrm{P}$ is the purpose for which $\mathrm{S}$ intends to use this gadget.

This pluridimensional account of scientific representation may be considered a considerable generalization of the original dyadic approach. Nevertheless, the original 2-dimensional approach and a 4-dimensional (or even $n$-dimensional, $n \geq 4$ ) approach may be considered to be of the same kind, namely, accounts that conceive of a representation as a relation between two (or more) ontologically different realms. Helmholtz's

\footnotetext{
13 Schlick, as one of the editors of Helmholtz's Epistemological Writings, approvingly comments on this remark: "The thought expressed here by Helmholtz is a fundamental insight of all epistemology. It lies at the base already of Plato's theory of Ideas... and likewise at that of the modern theory of science." Schlick in Helmholtz (1921, p. 179).
} 
original 2-worlds interpretation of Kant is only a prototype of a family of more elaborated accounts of this kind. ${ }^{14}$

\section{Structure-preserving representation as a relative a priori: the early Reichenbach's connecting principles}

The purest and technically most sophisticated structure-preserving representations appear in mathematics under various names, such as functions, homomorphisms, mappings, or, most recently and most generally, functors in the sense of category theory (cf. Mac Lane 1986; Bell 1986). ${ }^{15}$ It should be noted, however, that even in mathematics, this concept exhibits those pragmatic features that Giere and others have identified as essential for the pragmatic relevance of structure-preserving scientific representations, namely, that representations are set up for certain purposes. Representations do not exist an sich; they are intentional in a broad sense.

The early Reichenbach was the first to note that the issue of structure-preserving representations is closely related to an issue that has occupied philosophy of science for the last two hundred years, namely, the a priori elements in scientific knowledge (cf. Reichenbach 1920).

The virtually ubiquitous presence of (partially) structure-preserving representations (Zuordnungen) in empirical knowledge provides a good argument for the existence of an a priori ingredient: Structure preservation may be conceived as a kind of relativized Kantian a priori. That is to say, it may be fruitful for philosophy of science to conceive of the phenomenon of structure preservation as a kind of Kantian a priori. ${ }^{16}$ This thesis is in need of explication. For this purpose, it is expedient to take a closer look at the account of the relative a priori of the early Reichenbach (1920).

According to Reichenbach, within the context of any given theory, there is a sharp distinction between two essentially different types of axioms: Axioms of coordination and axioms of connection. Typical (empirical) axioms of connection are, for instance, the law $\mathrm{F}=\mathrm{ma}$ in Newtonian mechanics, the equation $\mathrm{pV}=\mathrm{kT}$ in the theory of ideal gases or, according Reichenbach, Einstein's equations of gravitation, which describe "the special mathematical relation of the physical variables $\mathrm{R}_{\mathrm{ik}}$ to the physical variables $\mathrm{T}_{\mathrm{ik}}$ and $\mathrm{g}_{\mathrm{ik}}$." (Reichenbach 1920, p. 54) ${ }^{17}$ From these axioms of connection, one has to distinguish the axioms (or principles) of coordination:

\footnotetext{
14 Indeed, one may consider Giere's tetradic account to be a late sophisticated member of this family of "Kantian" representations that began with Helmholtz's representation: W corresponds to Helmholtz's "wirkliche Welt", and X corresponds to his domain of "Erscheinungen".

15 Perhaps the most spectacular singular result of twentieth century mathematics concerning representation has been Stone's representation theorem that establishes a faithful representation of the category of Boolean algebras in terms of topological spaces by relating to every Boolean algebra B a topological space $\mathrm{St}(\mathrm{B})$ (cf. Johnstone 1982).

16 I do not claim that partial structure-preservation must be conceived as a kind of Kantian a priori. One may well ignore its Kantian aspects and treat it simply as a primitive feature of modern empirical theories. In my opinion, this approach amounts, however, to an incomplete conception.

17 They do not concern us in this paper, although they have traditionally been more prominent in philosophy of science than the more modest coordination axioms, such as the rules of arithmetic constitutitve for all kinds of measurements.
} 
The axioms of coordination ... do not connect certain variables of state with others but contain general rules according to which connections take place. In the equations of gravitation, the axioms of arithmetic are presupposed as rules of connection and are therefore coordinating principles of physics (Reichenbach 1920, p. 54).

At first glance, this claim may sound a bit confusing: Are the axioms of arithmetic both rules of connection AND coordinating principles? In some sense, yes: First, the axioms of arithmetic are rules of connection of mathematical objects, namely, they describe how numbers, vectors, and tensors (as objects of mathematics) are added, multiplied, and connected in other specific ways. Then, in a second step, these rules also serve as coordinating principles, as they also govern the physical variables to which the mathematical variables are coordinated.

The concept of (partial) structure preservation may help elucidate this issue. Consider the most elementary case of length measurement of a certain domain D of physical objects. According to the representational theory of measurement, this case amounts to a coordination $\phi$ between objects $d \in \mathrm{D}$ and (real) numbers $\mathrm{r} \in \mathrm{R}$ such that the connecting rules of both domains are respected. More precisely, the coordination $\varphi$ has to satisfy (among some other rules) the basic requirement of structure preservation:

$$
\varphi\left(\mathrm{d}_{1} \oplus \mathrm{d}_{2}\right)=\phi\left(\mathrm{d}_{1}\right)+\phi\left(\mathrm{d}_{2}\right)
$$

here $\oplus$ is the physical operation of concatenating material objects in an appropriate way, and + is the familiar operation of numerical addition. This requirement of extensionality may be considered a constitutive principle necessary for a magnitude that can be interpreted as length. A physical magnitude that does not satisfy it cannot be considered length. A slightly more complicated case is considered by Reichenbach:

[I]f a certain mathematical symbol is coordinated to a physical force, the properties of the mathematical vector must be ascribed to it in order to enable us to think of this force as an object. In this case the axioms referring to vector operations are constitutive principles, i.e., categories of physical concepts (Reichenbach 1920, p. 54)

Reichenbach's approach can be described generally as follows: connection axioms describe relations between objects of the same ontological realm-either between physical magnitudes or between mathematical objects; on the other hand, coordination axioms stipulate relations between mathematical objects and physical objects, respecting the respective connection axioms and thereby establishing a (partially) structure preservation between the physical and mathematical ones.

Coordinating axioms are constitutive for all kinds of scientific objects qua scientific objects. They are not apodictic but may change in the ongoing evolution of science. ${ }^{18}$ The task of the coordinating axioms of various kinds is to ensure the uniqueness of the coordination between mathematical concepts and physical objects (cf. Reichenbach

\footnotetext{
18 Reichenbach was, of course, not the first to discover them: they already appear, though not under this label, in the works of Helmholtz, Duhem and others, who did not distinguish them from connection axioms.
} 
1920, p. 57). Indeed, for Reichenbach to answer the question of how uniqueness of coordination is achieved was to answer the crucial question for any epistemology:

How it is possible to achieve such a coordination (Zuordnung) in a consistent manner? This question belongs in critical philosophy, for it is equivalent to Kant's question "How is natural science possible?" ... We should like to stress that the question is meaningful independently of any given answer and that there can be no epistemology that ignores it. ... (Reichenbach 1920, p. 46)

The first thing to note is that according to Reichenbach, Zuordnung in mathematics and Zuordnung in physics were essentially different:

The coordination performed in a physical proposition ... differs distinctly from other kinds of coordination (such as coordination in mathematics). For example, if two sets of points are given, we establish a correspondence between them by coordinating to every point of one set a point of the other set. For this purpose, the elements of each set must be defined; that is, for each element there must exist another definition in addition to that which determines the coordination to the other set. Reichenbach (1920, p. 37)

Actually, this model is an oversimplified model of how Zuordnung (coordination) works in modern mathematics. ${ }^{19}$ It allows Reichenbach, however, to draw a strict line between mathematical Zuordnung on the one hand and Zuordnung between mathematical concepts and physical objects on the other. According to him, the neat concept of structure-preserving representation-as it is characteristic for modern mathematics under different names such as (continuous) functions, homomorphisms, or functors-is relevant for matters representational in the empirical sciences only in a limited manner. Thus, the problem of coordination between the empirical and the mathematical would remain a problem for philosophy of science even if the issue of inner-mathematical representation is well understood.

Nevertheless, Reichenbach thinks it expedient to begin with a special case of a "difficult" mathematical (coordination) Zuordnung in order to eventually explain the essential difference between the two kinds of Zuordnung. I think it is useful to consider this case in some detail in order to understand the intricacies of Reichenbach's concept of Zuordnung.

His example is concerned with "the coordination of the rational fractions to the points of a straight line" (Reichenbach 1920, p. 37). First, he notes that all elements of the straight line are well defined in advance of the task of coordinating all rationals with (some of) them, since "we can say of any point of the plane whether or not it belongs to the real line" (ibid.) Moreover, the points of the straight line are linearly ordered. Thus, the representing mathematical structure of the straight line is, so to speak, already there, and all its elements and relations are explicitly given, which also holds for the rational numbers $\mathbf{Q}$ to be represented. Nevertheless, a unique Zuordnung of the rationals to the

\footnotetext{
19 Take for instance the already mentioned example of Stone's representation of Boolean algebras B as sets of "clopen" (= closed and open) subsets of a certain topological space St(B) called the Stone space of B. It is hard to see what it would mean for the elusive structure of the Stone space St(B) (defined with the help of B and the axiom of choice AC) to exist independently from B.
} 
reals seems not to be possible for several reasons. For example, as it stands, the choice of the unit is completely arbitrary. We may represent the rational number $1 \in \mathbf{Q}$ by any real number whatsoever, which renders the representation of $\mathbf{Q}$ by $\mathbf{R}$ quite arbitrary. As Reichenbach correctly noted, one has to find other relations of real numbers (and rational numbers) to achieve uniqueness of coordination. The point is that this problem is mathematical and can be solved mathematically. How this solution is to be achieved need not be described in detail. In contrast, the unique coordination of physical objects and mathematical concepts cannot be solved by purely mathematical means. Rather, as Reichenbach notes somewhat cryptically, in the empirical sciences

... we are faced with the strange fact that in the realm of cognition two sets are coordinated, one of which not only attains its order through this coordination, but whose elements are defined by means of this coordination (Reichenbach 1920, p. 40).

The coordination itself creates one of the sequences of elements to be coordinated, which seems to render impossible any kind uniqueness, since there are no mathematical or perceptual means to achieve it. As Reichenbach put it, "Perception does not determine reality". Hallucinations are more than nothing. It depends on the context whether or not they have to be taken into account.

Nevertheless, Reichenbach claims that there is a kind of determination of knowledge by experience that enables us to achieve a unique coordination between the empirical and the mathematical. This uniqueness, however, considerably differs from the purely mathematically defined uniqueness discussed before.

The only fact can be determined in physics whether two numerical values derived from two different measurements are the same. We cannot know whether a coordination with this result always refers to some element in the real world. But if the values obtained by the measurements are consistently the same, then the coordination possesses that property which we call truth or objective validity. Therefore, we define: Uniqueness of a cognitive coordination means that a physical variable of state is represented by the same value resulting from different empiricial data (Reichenbach 1920, p. 45).

For Reichenbach, the essential problem to solve for philosophy of science or epistemology is to answer the following question:

How is it possible to achieve such a (unique) coordination in a consistent manner?

This question belongs in critical philosophy, for it is equivalent to Kant's question "How is natural science possible?" (Reichenbach (1920, p. 75))

Reichenbach's answer to this question remains vague and unilluminating: "We see such a way (to answer this question) in the application of the method of logical analysis to epistemology." (ibid. 74). Then, instead of giving a precise explication of how the method of logical analysis achieves this, he is content to mention two rather different successful applications: First, he boasts that he carried out a successful logical analysis for the theory of probability (considered as a non-empirical theory); then, he credits Einstein as having achieved the analogous result for the theory of relativity. Thereby, Reichenbach contends that a truly modern philosophy of science can be characterized 
as a modernized Kantianism that is in close contact with science in the following sense:

The results discovered by the positive sciences in continuous contact with experience presuppose principles the detection of which by means of logical analysis is the task of philosophy (Reichenbach 1920, p. 75).

In summary, Reichenbach subscribed to a strict distinction between Zuordnung in mathematics and Zuordnung as a method of constitution in physics (and other empirical sciences). ${ }^{20}$ This stance is in stark opposition to the one that his teacher Cassirer had put forward, namely, that the constitutional methods in both realms are the same: In his seminal paper Kant und die moderne Mathematik (Cassirer 1907), Cassirer put it in this way:

Only when we have understood that the same foundational syntheses on which logic and mathematics rest also govern the scientific construction of experiential knowledge, that only they enable us to speak of a strict, lawful ordering among appearances and therewith of their objective meaning: only then the true justification of the principles is attained (Cassirer 1907, p. 44).

What exactly these same foundational syntheses are is left open by Cassirer here. It seems plausible to assume, however, that some kind of coordinating principles are among them. Cassirer agrees with Reichenbach in that philosophy has to be in close contact with science in order to fulfil this task.

\section{Overcoming scepticism: Cassirer's concept of homogeneous representation}

Rorty was not the first nor only one who distinguished between "representationalists" and "anti-representationalists" in order to organize the history of philosophy and particularly epistemology in broad outline. In Substance and Function, Cassirer (1910, p. 282ff) undertook a similar endeavor. Needless to say, Cassirer's conclusions with respect to the feasibility of representationalism considerably differed from that of Rorty.

In contrast to Rorty, Cassirer distinguished between an aporetic "metaphysical" concept of representation and a "good" critical one:

In metaphysical doctrines, the "presentation", (Vorstellung) refers to the object, which stands behind it. Thus the "sign" here is of an entirely different nature than the signified, and belongs to another realm of being. Precisely in this lies the real riddle of knowledge (Cassirer 1910, p. 282).

This conceptualization of representation (of which Helmholtz's two-worlds Kantianism is perhaps the clearest example) is threatened by an obvious skeptical objection:

\footnotetext{
20 Padovani claims that Reichenbach's concept of Zuordnung was originally (before 1920) inspired by the concept that Cassirer presented in his Kant und die moderne Mathematik (Cassirer 1907) and then elaborated in Substance and Function (Cassirer 1910) (cf. Padovani 2011).
} 
... for what assurance have we that the symbol of being, which we believe we have in our presentation, genuinely reproduces the content of being, and does not misrepresent its essential features? (Cassirer 1910, p. 284).

A "critical account" of representation (like that of Cassirer) is not exposed to this objection:

The new meaning, which the criticism of knowledge gives to the concept of representation, removes this danger. It is now recognized that each particular phase of experience has a "representative" character, in so far it refers to another and finally leads by progress according to rule to the totality of experience. But this reference beyond concerns only the transitions from one particular serial member to the totality, to which it belongs, and to the universal rule governing this totality. ... It places the individual in the system. ... (Cassirer 1910, p. 284).

In this way, Cassirer's approach, usually characterized as "neo-Kantian" or "idealistic" account, turns out to have something in common with pragmatism:

[Scientific] concepts are valid, not in that they copy a fixed, given being, but insofar as they contain a plan for possible constructions of unity which must be progressively verified in practice, in application to the empirical material. ... We need, not the objectivity of absolute things, but rather the objective determinateness of the method of experience (Cassirer 1910, p. 322).

In summary, the pragmatic component of Cassirer's account of the a priori is encapsulated in the claim that "valid" concepts contain "plans for possible constructions of unity". Concepts are "blueprints" for further experiences. In other words, they provide maps for the spaces of further possible actions and the experiences resulting from them. This can be formulated as the thesis that concepts serve as representations.

Like all plans, concepts are based on certain a priori assumptions. They are devices for achieving certain goals. For Cassirer, concepts were plans for constructing an evermore thorough unity of scientific knowledge. Hence, it does not seem inappropriate to characterize Cassirer as a "theoretical pragmatist" ${ }^{21}$ for whom the aim of scientific activity was not to produce a faithful description of the world but to bring about increasingly comprehensive and unifying experiences.

From a contemporary point of view, Cassirer's emphasis on coherence and comprehensiveness as the most important and most highly valued characteristics of the scientific enterprise may be criticized as biased. ${ }^{22}$ The important common feature of Cassirer's Neokantianism and Lewis's pragmatic scientific knowledge, however, is that action and evaluation are essentially connected (cf. Lewis 1946, p. 5). Their accounts

\footnotetext{
21 In Substance and Function (Cassirer 1910, p. 318ff), it is explicitly stated that the "critical theory of knowledge" (= Cassirer's) is in line with Dewey's.

22 The issue of the (dis)continuity of the evolution of scientific knowledge is vividly discussed in contemporary philosophy of science (cf. Friedman 2001; Chang 2008; Mormann 2012a, b). In his later philosophy, Cassirer is actually less of a continuist than has been generally recognized. For instance, in his last book on philosophy of science, Determinism and Indeterminism (Cassirer 1956 (1937)), he emphasized the necessity "that somewhere in the process of knowledge we have to acknowledge real "mutations" that lead to something new and independent." (Cassirer 1956 (1937), p. 191).
} 
differ in how much continuity and coherence they expect the ongoing progress of scientific to exhibits. As will be shown in the next section, Chang moves even further away from any continuism.

\section{Towards a pragmatic account of the a priori: clarence Irving Lewis and Hasok Chang}

During his day, Clarence Irving Lewis (1883-1964) was one of most prominent American philosophers. Today, he is lesser known than the other three great classical pragmatists Peirce, James and Dewey, so some introductory remarks on his life and philosophy may be in order. ${ }^{23}$ Lewis may be characterized as the most Kantian of all pragmatists, although of a rather peculiar kind. He is reported to have characterized himself as "a Kantian who disagrees with every sentence of the Critique of Pure Reason." Besides Peirce, he may be said to have been the "most logical" pragmatist. After having finished his dissertation The Place of Intuition in Knowledge (1911) under Josiah Royce, his research interests switched to logic. Much of his work sought to overcome the shortcomings of standard extensional logic. Indeed, Lewis was one of the founding fathers of modern modal logic. More generally, he addressed the question of what should be considered the "correct" logic of science or of our everyday reasoning as an empirical problem the solution to which had to take into account the empirical facts of the practice of scientific investigation.

A first sketch of his theory of a pragmatic a priori is to be found in his paper $A$ Pragmatic Conception of the A priori (1922). In mature form, it is presented in Mind and the World Order (1929, 1929 (1956)) (MWO). Further elaborations may be found in his later book, An Analysis of Knowledge and Valuation (1946).

Let us start with a quote from (MWO) in which he subscribed to a nonapodictic interpretation of the a priori rather similar to the one that Reichenbach had put forward earlier:

The a priori... represents the contribution of the mind itself to knowledge, it does not require that this mind be universal, or absolute... The determination of the a priori is in some sense like free choice and deliberate action (MWO, pp. 231, 233).

Similar Reichenbach's, Lewis's a priori kept only the constitutive element of its Kantian ancestor; apodicticity is given up, and intuition plays no role in it. For Lewis, the a priori was a variable that might change over time. Even the a priori principles of logic were not beyond the possibility of alteration. This possibility was not merely abstract:

\footnotetext{
23 For comprehensive presentations of Lewis's life and work, the reader may consult Murphey (2005) or Rosenthal (2007); for a succinct presentation of Lewis's philosophy and a comparison of his views with those of Carnap and Quine, the reader may consult Baldwin (2007). For a succinct, modern survey, see Misak's The American Pragmatists (Misak 2013). She locates Lewis's pragmatism very close to logical empiricism. Even more, she claims that "the logical empiricism drifted closer and closer to their pragmatist cousins until the view were almost indistinguishable" (Misak 2013, p. 254). On the other hand, she draws a strict line between Rorty's neo-pragmatism and the "classical” pragmatism of Peirce and Lewis (cf. Misak 2013, p. 231).
} 
Lewis was one of the leading figures in promoting alternative logics differing from that of the Principia Mathematica.

Although no longer apodictic, Lewis's a priori maintained a conditional kind of necessity. The a priori was true no matter what experience might bring. The acceptance of a concept as a priori was a matter of decision or legislation, something for which there were alternatives but for which the criteria are not empirical but pragmatic. This necessity of the a priori has nothing to do with inescapability:

The paradigm of the a priori in general is the definition. It has always been clear that the simplest and most obvious case of truth which can be known in advance of experience is the explicative proposition and those consequences of definition which can be derived by purely logical analysis.

...

If experience were other than it is, the definition and its corresponding classification might be inconvenient, useless, or fantastic, but it could not be false (MWO, p. 239).

For Lewis, the best examples for such analytical a priori were provided by mathematics. According to him, the traditional conceptions of the a priori are the "historical shadow of Euclidean geometry" (MWO, pp. 240-241). But, Euclidean geometry gave the wrong impression that the a priori was unique and apodictic. The invention of a plurality of non-Euclidean geometries evidenced that the true a priori of scientific knowledge was an a priori of a different kind, which lacked uniqueness and apodicticity (MWO, p. 242). Rather, an essential feature of the a priori component in knowledge was that it could have been chosen differently. Although mathematics provided a good example for a science in which the a priori element plays an important role, Lewis emphasized that the a priori element in the empirical sciences went far beyond the mathematical:

All order of sufficient importance to be worthy of the name of law depends eventually upon some ordering by mind. Without initial principles by which we guide our attack upon the welter of experience, it would remain forever chaotic and refractory. In every science there are fundamental laws which are a priori because they formulate just such definitive concepts or categorial tests by which alone investigation becomes possible (MWO, p. 254).

As an example of such an operational a priori, Lewis discussed Einstein's definition of simultaneity for events at a distance in detail. For him, it was a stipulation that one could make of one's own free-will in order to arrive at a definition of simultaneity (cf. MWO, p. 256). Hence, Einstein's operational definition of simultaneity was an a priori law. Only by presupposing such laws could one enter upon the investigation by which further (empirical) laws were sought, which led him to make the following sweeping generalization:

Indeed all definitions and all concepts exercise this function of prescribing fundamental law to whatever they denote, because everything which has a name is to be identified with certainty only over some stretch of time (MWO, p. 257). 
The a priori element in knowledge is present whenever there is classification, interpretation, or the distinction of real from unreal, which means that it is present in all knowledge (cf. MWO, p. 266). Lewis vigorously endorsed the thesis that a priori laws could be abandoned when the structure, which was built upon them, did not succeed in simplifying our interpretation of the phenomena. Thereby, he arrived at a kind of Kuhnian description of a revolutionary change in science forced by the pressure of new "anomalic" experience that does not fit well in the old framework:

Beyond the principles of logic and pure mathematics ... there must be further and more particular criteria of the real prior to any investigation of nature. Such definitions, fundamental principles and criteria the mind itself must supply before experiences can even begin to be intelligible. These represent more or less deeplying attitudes, which the human mind has taken in the light of its total experience up to date. But a newer and wider experience may bring about some alteration of these attitudes even though by themselves they dictate nothing as to the content of experience, and no experience can conceivably prove them invalid (MWO, p. 266).

Even if Lewis did not use this term, his account of a comprehensive a priori, which goes well beyond formal logic and mathematics, points towards a sort of transcendental logic similar to the one that Cassirer had put forward in his programmatic paper Cassirer (1907).

This brief survey of Lewis's pragmatic a priori suggests that it sketches a framework for the conceptual and practical activities and operations of a community of scientists for some time. The pragmatic a priori determined what was to be understood as a meaningful problem, what counted as a solution, what methods were considered admissible and what were the standards according to which the results were assessed. If the pressure of recalcitrant experiences became too strong, it could be given up and replaced by another other experiences. In summary, the Lewisian a priori exhibited certain similarities to a Kuhnian paradigm (cf. Kuhn 1962), although Lewis remains much less specific than Kuhn. ${ }^{24}$

In the paper Contingent Arguments for Metaphysical Principles (Chang 2008), the author endeavors to update Kant's transcendental arguments for the a priori in such a way that they take into account particular and contingent epistemic circumstances of the cognizing subject. According to Chang, such contingent arguments for metaphysical principles may be cast in the following form (cf. Chang 2008, p. 113).

If we want to engage in a certain epistemic activity, then we must presume the truth of some metaphysical principles.

\footnotetext{
24 An anonymous referee pointed out that Lewis's a priori is perhaps even closer to Hacking's concept of a "style of reasoning". Although this claim may be true, it should be noted that Hacking vigorously denies being a pragmatist despite subscribing to some theses of pragmatism. See his paper On not Being a pragmatist (Hacking 2007), which may be read as a short intellectual autobiography. There, he admits to have some admiration for Peirce and to owe some useful phrases to Dewey. C.I. Lewis, however, is not mentioned even once.

For a detailed discussion of Hacking's notion of "style" and its relation to notions such as Fleck's "thought style" in the landscape of historical epistemology, see Sciortino (2017), who proposes to conceive Hacking's notion of "style" as a historized Kantian approach.
} 
As a point of departure, Chang takes Lewis's "conceptual pragmatism" based on the central notion of the "pragmatic a priori" and goes further to propose that giving an account of the "epistemic and conceptualizing activities of an embodied subject", i.e., an epistemic subject that has to come to terms with the contingent conditions of a spatio-temporal material world in which it is living, is an essential task of a theory of the pragmatic a priori.

For such a subject, the a priori makes sense only in a contingent way, not as a universal condition of cognition in general, but as a local factor of particular brands of cognition (ibid. 122). Chang criticizes Friedman for sticking too closely to the Kantian universal and apodictic a priori and thereby ignoring the local character of our cognition. More precisely, Kant is accused of having been too much impressed by the then dominate Newtonianism, thereby conceiving some temporarily useful scientific ideas of limited scope as deep general "metaphysical truths" (ibid. 114).

After these general remarks, let us now consider a simple example of Chang's "contingent transcendental If-then-arguments", a version of which can already be found in Lewis (cf. Lewis 1922, pp. 233-234):

If we want to count things, then we have to assume

that the domain of things to counted is discrete.

Otherwise, the activity of counting is not only impossible but also unintelligible. In other words, discreteness of the domain to be counted is a metaphysical principle that we have to presuppose if we want to engage in the activity of counting. This necessity is a conditional pragmatic necessity. If we were jelly-fish, we would not engage in the activity of counting (cf. Lewis 1926) because our surroundings cannot be meaningfully conceptualized as discrete.

Counting is nothing but constructing a (partially defined) structure-preserving representation of the domain D of elements to be counted to a "counting domain" $\mathbf{N}$ consisting of natural numbers. A conditio sine qua non for the possibility of such a representation is the discreteness of the domain D. As Chang notes, the principle of discreteness is not empirical; it says nothing about the world itself, only that we need to take it as discrete if we want to count objects (cf. Chang 2008, p. 123). Sometimes, we may have some freedom to choose a discrete or continuous model. For instance, we may take time as discrete, consisting of temporal moments, or as a continuum, consisting of overlapping and infinitely divisible temporal intervals; similarly, space may be taken as discrete, consisting of discrete spatial points, or as a continuum, the basic constituents of which are infinitely divisible and overlapping regions. ${ }^{25}$

Among other things, a theory of the pragmatic a priori has the task of providing us with a comprehensive list of "principle-activity" pairs (henceforth, P/A-pairs). Some of those P/A-pairs are gathered in the following list (cf. Chang 2008, p. 125ff):

\footnotetext{
25 The relation between discrete and continuous conceptualizations may sometimes be rendered precise with the help of "pointless" topology (cf. Gierz et al. 2005). More precisely, for a topological space X, one may take discrete "points" $\mathrm{x} \in \mathrm{X}$ or "regular open regions" $\mathrm{U} \in \mathrm{OX}$ as basic building blocks of the space X. For "well behaved spaces", these two models are equivalent in a precise sense (cf. Gierz et al. 2005). As is well known, the first to note this possibility, although in a somewhat vague manner, was Whitehead in Process and Reality (Whitehead 1929 (1985)).
} 
- Discreteness/Counting

- Sufficient Reason/Explanation

- Transitivity/Ordering
- Uniform Consequence/Prediction

- Subsistence/Narration

- Non-Contradiction/Assertion

Cognitively relevant actions in sciences such as mathematics, physics, biology, history or any other science presuppose the meaningfulness of activities like these. For instance, the attempts of ordering objects, processes, etc. makes sense only if one presupposes that the intended relation of ordering is transitive; or, if we are engaged in giving explanations, we have to presuppose that there exist sufficient reasons for certain states of affairs. Considering examples like these (cf. Mormann 2012a, b), it does not seem too far-fetched to consider them all as some kind of structure-constituting representations.

Doing science in some way or other cannot be described as carrying out any of these activities in isolation. Rather, P/A-pairs show up in complex systems that can be separated into isolated P/A-pairs as they appear in such a list only for methodological reasons. It does not seem implausible to conceive such complex systems kinds of Kuhnian paradigms that determine the scientific practice of a scientific community at a certain time. A scientific revolution takes place when essential components of such a system of P/A-pairs are replaced by new ones under the pressure of anomalies.

An important trigger for changing an established system of pragmatic a priori elements is the invention of new machines, new measuring instruments and new experimental set ups. Such inventions often lead to totally new problems, perspectives, and solutions. As examples, Lewis briefly mentioned the inventions of the telescope and microscope that brought about permanent changes to our categories of perception (cf. MWO, p. 268).

Since the advent of "Big Science", the importance of this kind of an "instrumental a priori" has steadily grown: one may think of a particle colliders or the new types of protein sequencers in molecular biology. These machines allow us to formulate questions and solve problems that did not make sense before these devices came into being. Another type of machine-based pragmatic a priori is provided by the various novel methods of calculation and simulation that are indispensable tools for the constitution of many results in the advanced empirical sciences. Chang's P/A-pairs make explicit a priori principles that are necessary to carry out all kinds of epistemic activities relevant for science.

Chang's paper offers only a sketch of some of these P/A-pairs. Elaborating Chang's proposal would be the task for a comprehensive theory of the role of the a priori in modern science. In Mormann (2012a, b), it is pointed out that Chang's P/A-pairs may be fruitfully related to some recent developments in cognitive science, in particular Lakoff's and Núñez's theory of conceptual metaphors that guide the contingent embodied rationality of creatures like us (cf. Lakoff 1987; Lakoff and Núñez 2000). It is shown that conceptual metaphors, and thereby P/A-pairs, have an elegant formal explication in terms of functors in the sense of category theory (cf. Awodey 2006; Mac 
Lane 1986). ${ }^{26}$ Here is no place to spell this explication out in detail, it may be enough to say that such would bring us back to the topic with which we started, namely, the issue of structure-preserving representations. After all, functors can be conceived as partially structure-preserving maps between one local conceptual universe and another (cf. Bell 1986).

Summarizing, we may say-against Rorty, who claimed the concept of representation to be obsolete-that there are good reasons to maintain the thesis that the issue of representation will remain a central issue of philosophy of science and epistemology. It seems plausible to conjecture that this thesis particularly holds due to the fact that the issue of structure-preserving representation is closely related to classical philosophical topics such as a theory of the a priori and a theory of constitution (cf. Carnap 1928; Coffa 1991, p. 214ff).

\section{References}

Awodey, S. (2006). Category theory. Oxford: Oxford University Press.

Baldwin, T. (2007). C.I. Lewis: Pragmatism and analysis. In M. Beaney (Ed.), The analytic turn: Analysis in early analytic philosophy and phenomenology (pp. 178-195). London: Routledge.

Bell, J. L. (1986). From absolute to local mathematics. Synthese, 69, 409-426.

Boniolo, G. (2007). On scientific representations: From Kant to a new philosophy of science. Basingstoke: Palgrave-MacMillan.

Carnap, R. (1928). Der logische Aufbau der Welt, Berlin, Weltkreis Verlag. Second edition Hamburg, Meiner (R. George as The Logical Structure of the World, Trans.). Berkeley and Los Angeles: University of California Press (Aufbau).

Cassirer, E. (1907). Kant und die moderne Mathematik. Kant-Studien, 12, 1-49.

Cassirer, E. 1910 (1953). Substance and function. New York: Dover.

Cassirer, E. 1956 (1937). Determinism and indeterminism in modern physics. Historical and Systematic Studies. New Haven: Yale University Press.

Chang, H. (2008). Contingent transcendental arguments for metaphysical principles. In M. Massimi (Ed.), Kant and philosophy of science today (pp. 113-133). London: Royal Institute of Philosophy. (Supplement 63).

Coffa, A. (1991). The semantic tradition from Kant to Carnap. In L. Wessels (Ed.), To the Vienna Station. Cambridge: Cambridge University Press.

Duhem, P. 1954 (1906). The aim and structure of physical theory. Princeton: Princeton University Press.

French, S. (2014). The structure of the world, metaphysics and representation. Oxford: Oxford University Press.

Friedman, M. (1997). Helmholtz' Zeichentheorie and Schlick’s Allgemeine Erkenntnislehre: Early logical empiricism and its Nineteenth-Century background. Philosophical Topics, 25, 19-50.

Friedman, M. (1999a). Reconsidering logical positivism. Cambridge: Cambridge University Press.

Friedman, M. (1999b). Geometry, convention, and the relativized a priori: Reichenbach, Schlick, and Carnap. In M. Friedman (Ed.), Reconsidering logical positivism (pp. 59-71). Cambridge: Cambridge University Press.

Friedman, M. (2001). Dynamics of reason. Stanford, CA: CSLI Publications.

Giere, R. (2004). How models are used to represent reality. Philosophy of Science, 71(5), 742-752.

Giere, R. N. (2006). Scientific perspectivism. Chicago: Chicago University Press.

\footnotetext{
${ }^{26}$ Indeed, Saunders Mac Lane, one of the leading mathematicians of the twentieth century, gave a rather comprehensive list of "metaphysical" principles on which mathematical knowledge and its application is based, see his Mathematics - Form and Function (1986), "especially written for philosophers of mathematics". Mac Lane's list considerably overlaps that of Chang, although Chang seems unfamiliar with Mac Lane's work.
} 
Gierz, G., Hofmann, K. H., Keimel, K., Lawson, J. D., Mislove, M. W., \& Scott, D. S. (2005). Continuous lattices and domains. Cambridge: Cambridge University Press.

Hacking, I. (1983). Representing and intervening. Introductory Topics in the Philosophy of Natural Science. Cambridge: Cambridge University Press.

Hacking, I. (2007). On not being a pragmatist. In C. Misak (Ed.), New pragmatists (pp. 32-49). Oxford: Clarendon Press.

Heidelberger, M. (1998). From Helmholtz's philosophy of science to Hertz's picture theory. In D. Baird, R. I. G. Hughes, \& A. Nordmann (Eds.), Heinrich Hertz classical physicist, modern philosopher, Boston studies in the philosophy of science (Vol. 198, pp. 9-24). Boston: Springer.

Hertz, H. (1894). Die Prinzipien der Mechanik in neuem Zusammenhange dargestellt. Leipzig: Barth. Gesammelte Werke 3 (1910). Translated as The principles of mechanics presented in a new form. London: Macmillan.

Johnstone, P. (1982). Stone spaces. Cambridge: Cambridge University Press.

Kant, I. 1998 (1787). Critique of pure reason. Cambridge: Cambridge University Press.

Kuhn, T. (1962). The structure of scientific revolutions (2nd ed.). Chicago: University of Chicago Press, 1970.

Lakoff, G. (1987). Women, fire, and dangerous things: What categories reveal about the mind. Chicago: The University of Chicago Press.

Lakoff, G., \& Núñez, R. E. (2000). Where mathematics comes from: How the embodied mind brings mathematics into being. New York: Basic Books.

Lewis, C. I. (1922). A pragmatic conception of the a priori. Journal of Philosophy, 20, 169-177. (Reprinted in Lewis 1970, 231-239).

Lewis, C. I. (1926). The pragmatic element in knowledge. Publications in philosophy (Vol. 6, pp. 205-227). California: University of California. (reprinted in Lewis 1970, 240-257).

Lewis, C. I. 1929 (1956). Mind and the world order: Outline of a theory of knowledge. New York: Dover.

Lewis, C. I. (1929). Mind and the world order: Outline of a theory of knowledge. New York: Dover.

Lewis, C. I. (1946). An analysis of knowledge and valuation. Chicago: Open Court.

Lewis, C. I. (1970). In J. D. Goheen, \& J. L. Motherhead (Eds.), Collected papers of clarence Irving Lewis. Stanford: Stanford University Press.

Lützen, J. (2005). Mechanistic images in geometric form, Heinrich Hertz' Principles of Mechanics. Oxford: Oxford University Press.

Mac Lane, S. (1986). Mathematics: Form and function. Berlin: Springer.

Majer, U. (1998). Heinrich Hertz's picture-conception of theories: Its elaboration by Hilbert, Weyl, and Ramsey. In D. Baird, R. I. G. Hughes, \& A. Nordmann (Eds.), Heinrich Hertz. Classical physicist, modern philosopher, Boston studies in the philosophy of science (Vol. 198, pp. 225-245). Berlin: Springer.

Misak, C. (2013). The American pragmatists. Oxford: Oxford University Press.

Mormann, T. (2012a). Toward a theory of the pragmatic a priori. In R. Creath (Ed.), Rudolf Carnap and the legacy of logical empiricism, Vienna circle Institute yearbook (Vol. 16, pp. 11-132). Berlin: Springer.

Mormann, T. (2012b). A place for pragmatism in the dynamics of reason? Studies in History and Philosophy of Science Part A, 43(1), 27-37.

Murphey, G. M. (2005). C.I. Lewis. The last great pragmatist. New York: State University Press of New York.

Oberdan, T. (2015). From Helmholtz to Schlick: The evolution of the sign-theory of perception. Studies in History and Philosophy of Science, 50, 35-43.

Padovani, F. (2011). Relativizing the relativized a priori: Reichenbach's axioms of coordination divided. Synthese, 181, 41-62.

Redhead, M. (1975). Symmetry in intertheory relations. Synthese, 32, 77-112.

Reichenbach, H. (1920). Relativitätstheorie und Erkenntnis A priori. Berlin: Springer. (Maria Reichenbach as The theory of relativity and a priori knowledge, 1965, Trans.). Berkeley: University of California Press.

Reichenbach, H. (1924). Axiomatik der relativistischen Raum-Zeit-Lehre. Braunschweig: Vieweg. (M. Reichenbach as Axiomatization of the theory of relativity, 1969, Trans.). Los Angeles: University of California Press.

Reichenbach, H. (1928). Philosophie der Raum-Zeit-Lehre. Berlin: de Gruyter. (M. Reichenbach \& J. Freund as The philosophy of space and time, 1969, Trans). New York: Dover.

Rheinberger, H.-J. (2010). On historicizing epistemology. An essay. Stanford: Stanford University Press. 
Rorty, R. (1991). Objectivity, relativism, and truth. Philosophical papers (Vol. 1). Cambridge: Cambridge University Press.

Rorty, R. (1993). An antirepresentationalist view: Comments on Richard Miller, van Fraassen/Sigman, and Churchland. In G. Levine (Ed.), Realism and representation (pp. 124-133). Madison, WI: The University of Wisconsin Press.

Rosenthal, S. B. (2007). CI Lewis in focus. The pulse of pragmatism. Bloomington, IN: Indiana University Press.

Ryckman, T. (2005). The reign of relativity. Philosophy in physics 1915-1925. New York: Oxford University Press.

Sciortino, L. (2017). On Ian Hacking's Notion of Style of Reasoning. Erkenntnis, 82, 243-264.

van Fraassen, B. (2006). Scientific representation. Paradoxes of perspectives. Oxford: Clarendon Press.

Von Helmholtz, H. (1878). Über die Tatsachen, die der Geometrie zugrunde liegen (On the facts underlying geometry). In Helmholtz (1977), pp. 39-58.

Von Helmholtz, H. (1977). Epistemological writings. The Paul Hertz/Moritz Schlick centenary edition of 1921, with notes and commentary by the editors (Malcolm F. Lowe, Trans.), Boston Studies in the Philosophy of Science, (Vol. 37). Dordrecht: Reidel.

Whitehead, A. N. 1929 (1985). In D. R. Griffin \& D. W. Sherburne (Eds.), Process and reality, corrected edition. New York: The Free Press. 